\title{
Conditions to induce water repellency in soils with dimethyldichlorosilane
}

\author{
S. H. Y. $\mathrm{NG}^{*}$ and S. D. N. LOURENÇO*
}

\begin{abstract}
Dimethyldichlorosilane has been used as a hydrophobising agent for various applications, one of which is the treatment of soils. In geotechnical engineering, synthetic water-repellent soils can be used in barriers or ground improvement because of their wettability properties. This note examines the effect of dimethyldichlorosilane concentration on the soil type and time-dependent effects by means of contact angles measurements using the sessile drop method. The results reveal that the presence of organic matter, residual water and other non-mineral matter hinders the effectiveness of the treatment. Treated clean soil particle surfaces from crushed rocks achieve an immediate and high degree of water repellency.
\end{abstract}

KEYWORDS: geosynthetics; ground improvement; particle-scale behaviour; sands

\section{INTRODUCTION}

Water-repellent or hydrophobic soils, those with contact angles $>90^{\circ}$, have been employed in water harvesting in dry regions (Fink et al., 1980). In slopes, natural water-repellent soils reduce infiltration, increase surface runoff (Doerr et al., 2000) and may inhibit vegetation growth (Osborn et al., 1964). As water repellency can be induced in soils, opportunities arise for their use as synthetic water-repellent soils in impermeable or semi-permeable barriers in geotechnical applications. As opposed to clays, water-repellent sands have the unique advantage of remaining volumetrically stable when dried or wetted excessively.

Dimethyldichlorosilane (DMDCS), with composition $\left(\mathrm{CH}_{3}\right)_{2} \mathrm{SiCl}_{2}$, is a known hydrophobising agent used for various applications, from treating silica and glass surfaces (Gao \& McCarthy, 2006) to ultra-water-repellent films (Shen et al., 2012; Soeno et al., 2004). In soil science, Bachmann et al. (2000) were among the first to use DMDCS to form a hydrophobic coating on soil samples. However, most studies only considered the hydrophobising capacity of DMDCS, with little consideration given to details such as the concentration required to attain a certain degree of water repellency, the effect of soil type and other soil characteristics.

The basic mechanism of the DMDCS treatment to induce water repellency in dry soils is based on the reaction of DMDCS with water menisci or water vapour to form polydimethylsiloxane (PDMS) and hydrochloric acid $(\mathrm{HCl})$ (Ju et al., 2008).

$$
n\left[\left(\mathrm{CH}_{3}\right)_{2} \mathrm{SiCl}_{2}\right]+n\left[\mathrm{H}_{2} \mathrm{O}\right] \rightarrow\left[\left(\mathrm{CH}_{3}\right)_{2} \mathrm{SiO}\right]_{n}+2 n \mathrm{HCl}
$$

where $n$ is the number of DMDCS repeating units. PDMS then interacts with the abundant polar groups on the soil particle surface, usually made up of a hydroxyl group $(-\mathrm{OH})$ (Goebel et al., 2007), leading to the formation of an outward-oriented hydrophobic methyl group $\left(-\mathrm{CH}_{3}\right)$ (Fig. 1). Other silane compounds, such as $n$-octyltriethoxysilane, have also been used to induce water repellency in soils (Byun et al., 2011;

Manuscript received 5 August 2015; revised manuscript accepted 30 October 2015. Published online ahead of print 14 December 2015.

Discussion on this paper closes on 1 October 2016, for further details see p. ii.

* Department of Civil Engineering, The University of Hong Kong, Pokfulam, Hong Kong SAR, People's Republic of China.
Lee et al., 2015). For this study, DMDCS was preferred owing to the simplicity of sample preparation (the chemical is added directly to the soil). Organic acids such as stearic acid (Lourenço et al., 2015a), oleic acid (Wijewardana et al., 2015) and waxes (Bardet et al., 2014) were considered, but there is uncertainty regarding their stability with time.

Bachmann et al. (2000) found that contact angles $\sim 90^{\circ} \mathrm{can}$ be induced with $7.5 \mathrm{ml}$ DMDCS per $\mathrm{kg}$ of sand and $50 \mathrm{ml}$ DMDCS per $\mathrm{kg}$ of silt, with the difference assumed to be related to the higher surface area of the silt to the sand. However, other factors require consideration. Water repellency induced by DMDCS is assumed to be permanent, unlike natural soil water repellency that is time dependent and sensitive to the environment (relative humidity and ambient air temperature). The application of DMDCS has been mostly in clean sands; natural and infrastructure soils have organic matter, microorganisms and roots, which may alter the outcome.

To define the conditions that maximise the water-repellent effect of DMDCS in soils, the specific objectives are to (a) determine the relation between contact angles and DMDCS concentration, and $(b)$ evaluate the contact angle stability after the treatment (i.e. the effect of time on contact angles) for different soils (particle size distribution and components).

\section{MATERIALS AND METHODS \\ Natural and replicated soils}

To ascertain the influence of the particle size distribution, four samples including three natural soils and one industrial soil were tested: a surface fine sand (SFS), a surface coarse sand (SCS), alluvium (ALL) and Leighton Buzzard sand (LBS). The natural soils SFS and SCS were collected from the Ap Lei Chau Formation (volcanic tuff) on Hong Kong Island. Samples were collected at $2 \mathrm{~cm}$ below the surface and sealed in plastic bags. ALL was collected at the same depth from the Fanling Formation in the New Territories, Hong Kong. Samples were sieved at $1.18 \mathrm{~mm}$ mesh size and air dried (soil water repellency is temperature dependent (Doerr et al., 2000)).

To investigate the influence of the soil components (e.g. minerals, organic matter), the same four materials were replicated from freshly crushed granite in the same proportions in order to isolate the mineral particles and to 


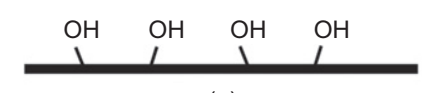

(a)

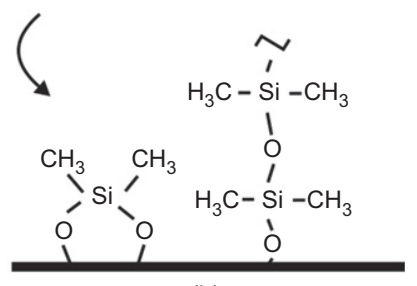

(b)

Fig. 1. Possible molecular configurations of the (a) natural soil particle surface and (b) treated soil particle surface

obtain the equivalent grain-size distributions (the fraction $<63 \mu \mathrm{m}$ was not measured). These are named repSFS, repSCS, repALL, repLBS ('rep' for replicated). All samples, natural and replicated were assumed to have similar mineralogy as they all originated from Hong Kong where the geology is mostly igneous. The particle size distribution is presented in Fig. 2. The field organic content (obtained by the loss on ignition test at a temperature of $550^{\circ} \mathrm{C}$ for $2 \mathrm{~h}$ ), air-dried water content and $D_{50}$ for all samples are available in Table 1.

\section{Silanisation}

The soil treatment with DMDCS involves the addition of a specific amount of DMDCS to soil samples $(\sim 100 \mathrm{~g}$ of air-dried soil) with a micropipette and stirring for $\sim 30 \mathrm{~s}$ in a fume cupboard to avoid the hydrogen chloride $(\mathrm{HCl})$ gas. All eight samples were treated with $0 \cdot 5 \%, 1 \%, 1 \cdot 5 \%, 2 \%, 2 \cdot 5 \%$

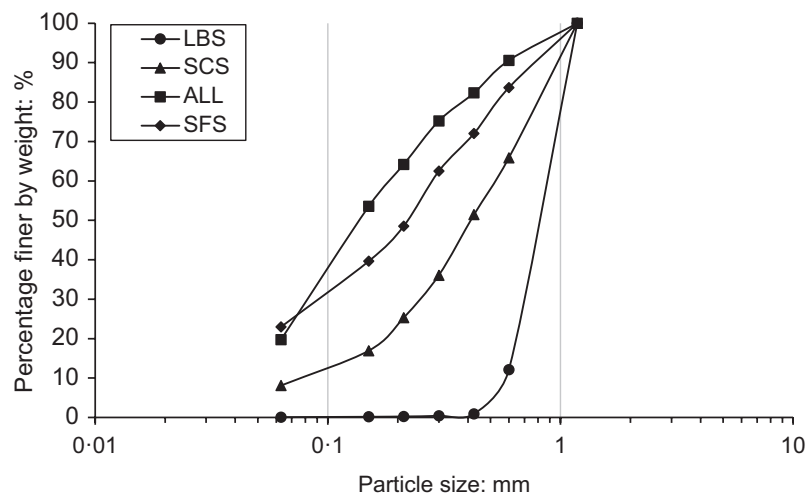

Fig. 2. Particle size distribution for all soils and $3 \%$ by soil mass of DMDCS and the contact angles were measured 3 days after the preparation (to account for any short-term fluctuations). To further study the water-repellent behaviour at low DMDCS concentrations, LBS was treated with $0.005 \%, 0.008 \%, 0.01 \%, 0.02 \%, 0.05 \%, 0.1 \%, 0.15 \%$ and $0 \cdot 25 \%$ by soil mass of DMDCS.

A second set of experiments was conducted to investigate the time stability of water repellency, that is, any time-related fluctuations. All eight samples were treated at different concentrations ( $1 \%$ and $2 \%$ by soil mass of DMDCS) and contact angle measurements were performed $1 \mathrm{~h}, 50 \mathrm{~h}, 150 \mathrm{~h}$ and $214 \mathrm{~h}$ after treatment.

\section{Measurement of soil water repellency}

Soil water repellency was determined by means of contact angle measurements with the sessile drop method (SDM), which is widely used in soil and materials science, and assessed by an index test, the water drop penetration time test (WDPT).

The WDPT assesses the persistency of water repellency of a soil surface (Doerr et al., 2000). Based on the time for a water drop to infiltrate, the samples are classified as wettable $(<5 \mathrm{~s})$, slightly water repellent (5-60 s), moderately water repellent (61-600 s), severely water repellent $(601-3600 \mathrm{~s})$ and extremely water repellent (3601-18 000 s) (Bisdom et al., 1993). The WDPT test was conducted 3 days after the soil treatment (the same for the SDM). The procedure consists of filling a Petri dish $(60 \mathrm{~mm} \times 15 \mathrm{~mm})$ with treated soil, levelling the excess to the edge with a spatula, adding an $80 \mu \mathrm{l}$ water drop onto the sample surface and recording the infiltration time; this is repeated three times to determine the median and the water-repellency rating.

The SDM measures the apparent contact angle (ACA) from the tangent of the three-phase point of a water drop on a layer of particles. 'Apparent' refers to the combined effect of the intrinsic material wettability and particle and layer roughness, that is, the heterogeneity of the layer surface (Lourenço et al., 2015b). ACAs were measured with a charge-coupled device equipped contact angle microscope (DSA 25, Krüss, Germany). The procedure consists of attaching a double-sided adhesive tape to a glass slide and adding the soil particles onto the tape evenly. Excess particles are removed by shaking the slide (Bachmann et al., 2000). A drop of deionised water of volume $\sim 10 \mu \mathrm{l}$ is placed on the glass slide while recording a video. The ACA is measured with the integrated software (version 1.92.1.1) from the initial video frames, typically within the first $30 \mathrm{~ms}$, which is essential for wettable materials where water infiltrates immediately. To take into account the variability

Table 1. Soil characteristics and selected results for the WDPT and SDM

\begin{tabular}{|c|c|c|c|c|c|c|c|c|}
\hline \multirow[t]{2}{*}{$\begin{array}{l}\text { Natural and } \\
\text { replicated samples }\end{array}$} & \multicolumn{3}{|c|}{ Soil characteristics } & \multicolumn{3}{|c|}{ Water repellency classification } & \multicolumn{2}{|c|}{$\begin{array}{l}\text { Critical percentage of } \\
\text { DMDCS to induce } \\
\text { maximum water } \\
\text { repellency }\end{array}$} \\
\hline & $\begin{array}{c}\text { Organic } \\
\text { content: } \%\end{array}$ & $\begin{array}{c}\text { Air-dried water } \\
\text { content: } \%\end{array}$ & $\begin{array}{l}D_{50}: \\
\mu \mathrm{m}\end{array}$ & Untreated & $\begin{array}{l}0 \cdot 5 \% \\
\text { DMDCS }\end{array}$ & $\begin{array}{l}3 \% \\
\text { DMDCS }\end{array}$ & WDPT: \% & SDM: $\%$ \\
\hline $\begin{array}{l}\text { LBS } \\
\text { repLBS } \\
\text { SCS } \\
\text { repSCS } \\
\text { SFS } \\
\text { repSFS } \\
\text { ALL } \\
\text { repALL }\end{array}$ & $\begin{array}{l}0 \cdot 21 \\
0 \cdot 60 \\
4 \cdot 59 \\
0.58 \\
6 \cdot 11 \\
0 \cdot 71 \\
3 \cdot 58 \\
0.67\end{array}$ & $\begin{array}{l}0 \cdot 24 \\
0 \cdot 39 \\
1 \cdot 77 \\
0 \cdot 53 \\
3 \cdot 23 \\
0 \cdot 41 \\
1 \cdot 09 \\
0 \cdot 62\end{array}$ & $\begin{array}{l}820 \\
820 \\
425 \\
425 \\
225 \\
225 \\
140 \\
140\end{array}$ & $\begin{array}{l}\text { Wettable } \\
\text { Wettable } \\
\text { Wettable } \\
\text { Wettable } \\
\text { Slight } \\
\text { Wettable } \\
\text { Wettable } \\
\text { Wettable }\end{array}$ & $\begin{array}{l}\text { Extreme } \\
\text { Extreme } \\
\text { Extreme } \\
\text { Extreme } \\
\text { Extreme } \\
\text { Extreme } \\
\text { Slight } \\
\text { Extreme }\end{array}$ & $\begin{array}{l}\text { Extreme } \\
\text { Extreme } \\
\text { Extreme } \\
\text { Extreme } \\
\text { Extreme } \\
\text { Extreme } \\
\text { Extreme } \\
\text { Extreme }\end{array}$ & $\begin{array}{l}<0 \cdot 005 \\
<0 \cdot 5 \\
\sim 2 \\
<0 \cdot 5 \\
\sim 1 \\
<0 \cdot 5 \\
\sim 1 \\
<0 \cdot 5\end{array}$ & $\begin{array}{l}<0.005 \\
<0.5 \\
\sim 2.5 \\
<0.5 \\
\sim 2 \\
<0.5 \\
\sim 1.5 \\
<0.5\end{array}$ \\
\hline
\end{tabular}


associated with the ACA magnitude, a minimum of ten measurements were carried out on each slide, after which the mean and standard deviation were computed. The air temperature and relative humidity - were $23 \cdot 6 \pm 0 \cdot 5^{\circ} \mathrm{C}$ and $58 \cdot 2 \pm 2 \cdot 6 \%$, respectively. No samples were reused.

\section{RESULTS AND DISCUSSION}

The results revealed that, for all replicated samples, the ACA reached the maximum value of $137^{\circ}-143^{\circ}$ at $0.5 \%$ DMDCS, remaining constant at higher DMDCS concentrations (Fig. 3). For the natural samples SCS and ALL, ACAs were substantially smaller than the equivalent repSCS and repALL, achieving $84^{\circ}$ at $0.5 \%$ DMDCS, and increasing up to $\sim 140^{\circ}$ at $3 \%$ DMDCS. Sample SFS was the only one to show slight water repellency before treatment $\left(\mathrm{ACA}=82^{\circ}\right)$. Similarly to samples SCS and ALL, SFS also had a lower ACA than repSFS at high concentrations, $121^{\circ}$ to $141^{\circ}$. For LBS, the ACA reached the maximum at $112^{\circ}$ with no further increase.

The results suggest that the air-dried water content and organic matter may have altered the water repellency of the soil. Comparing samples SCS to repSCS, SFS to repSFS and ALL to repALL, the particle size distributions were identical, with the major difference being the higher water and organic content for the natural soil samples (Table 1). Natural samples reached the maximum water repellency in the range $2-3 \%$ DMDCS for a water content of $1 \cdot 1-3 \cdot 2 \%$ and organic content of $3 \cdot 6-6 \cdot 1 \%$, while all replicated samples reached the maximum water repellency at $<0.5 \%$ DMDCS for $0 \cdot 4-0 \cdot 6 \%$ water content and $0 \cdot 6-0 \cdot 7 \%$ organic content. This response is further substantiated by the behaviour of LBS, where the stability of the ACA matched the low water and organic content, $0 \cdot 2 \%$ for both.

Table 1 shows that the majority of the treated samples were classified as extremely water repellent (Doerr, 1998), even at low percentages of DMDCS. With $0.5 \%$ and $3 \%$ DMDCS as a comparison, Table 1 shows that all natural samples were wettable before treatment, achieving extreme water repellency at $0.5 \%$ and $3 \%$ DMDCS, with the exception of SFS and ALL. All replicated samples and LBS displayed extreme water repellency at $0 \cdot 5 \%$ and $3 \%$ DMDCS.

The critical percentage of DMDCS required to induce the maximum water repellency diverged slightly across the samples. According to the WDPT and SDM data (Table 1), the replicated samples and LBS showed maximum water repellency at the lowest concentration $(<0.5 \%)$. In general, the critical percentage of DMDCS for the WDPT test was $0 \cdot 5 \%$ to $1 \%$ lower than the SDM test for SCS, SFS and ALL.

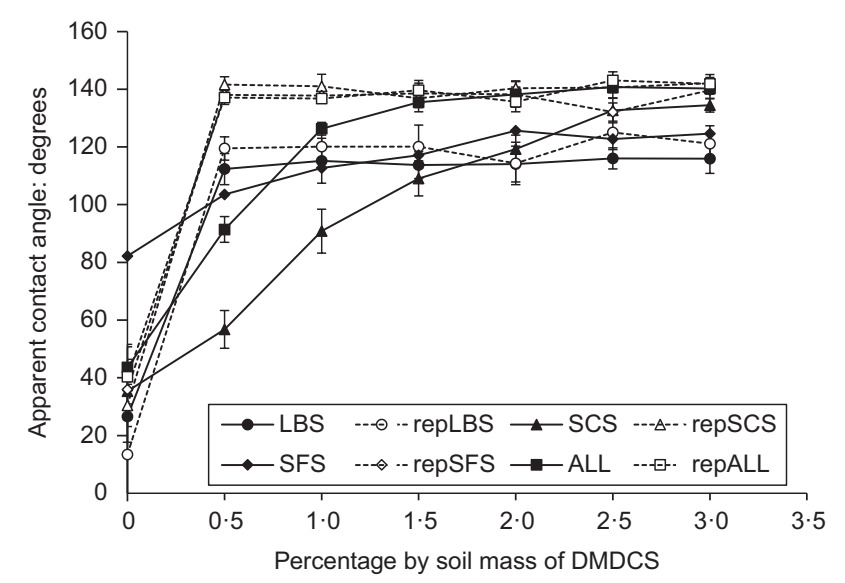

Fig. 3. Apparent contact angles for natural and replicated samples at increasing percentages by soil mass of DMDCS
However, the critical percentage of DMDCS was not achieved in any of the replicated samples. Further tests were carried out at low concentrations for LBS, revealing that the water repellency was already at the maximum ACA at $0 \cdot 005 \%$ DMDCS (Fig. 4).

The ACA measurements with time revealed distinctive responses for the natural and replicated samples (Figs 5(a) and 5(b)). The results matched the previous findings on the effect of water content and organic matter, with samples SFS, SCS and ALL showing that the degree of water repellency increases after treatment. For instance, the increase in ACA immediately after treatment, after $50 \mathrm{~h}$ and $215 \mathrm{~h}$ was,

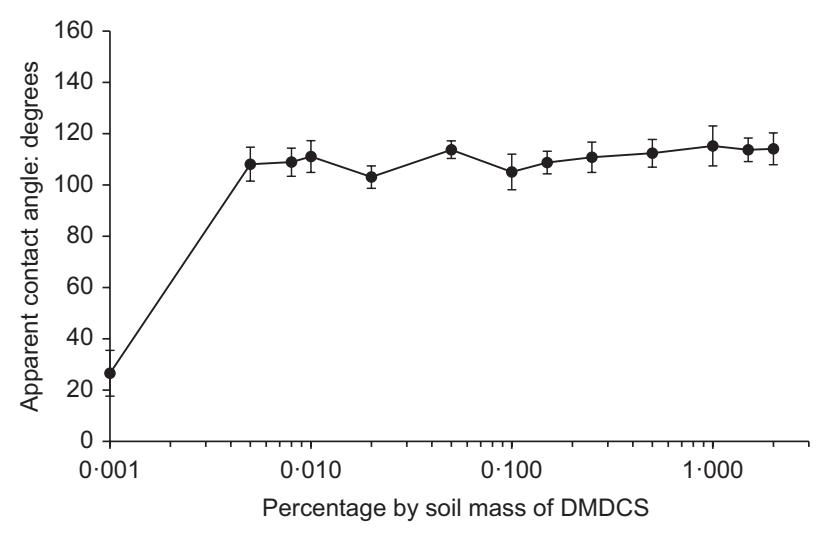

Fig. 4. Apparent contact angles for LBS at low percentages by soil mass of DMDCS

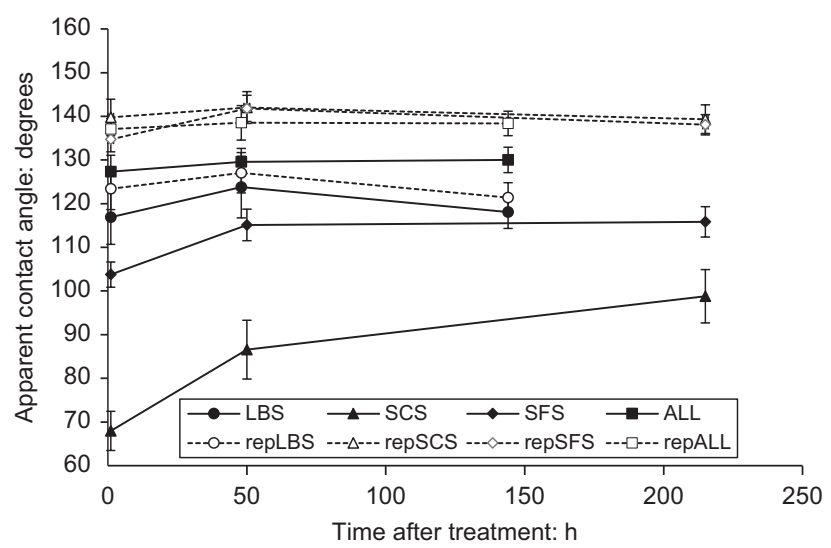

(a)

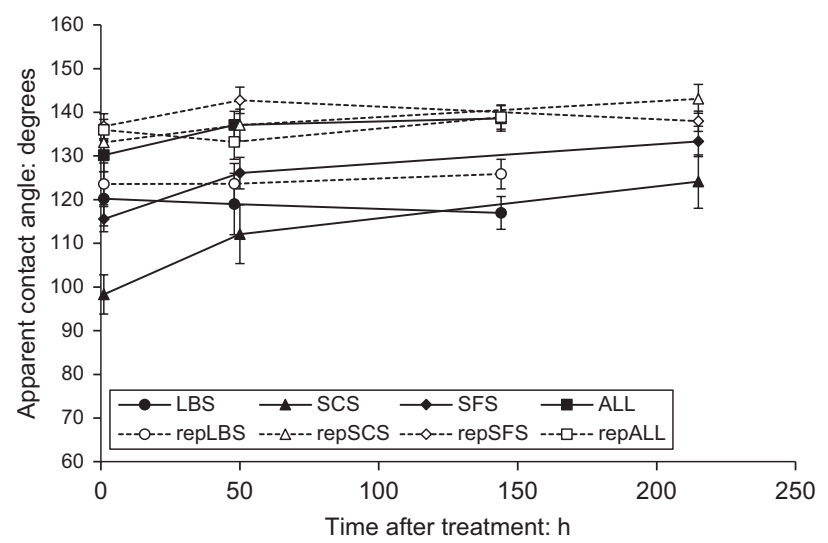

(b)

Fig. 5. Apparent contact angles with time after the soil treatment for the natural and replicated samples: (a) for $1 \%$ by soil mass of DMDCS; (b) for $2 \%$ by soil mass of DMDCS 
respectively, $68^{\circ}, 87^{\circ}, 98^{\circ}$ for $1 \%$ DMDCS in SCS and $140^{\circ}$, $142^{\circ}, 139^{\circ}$ for $1 \%$ DMDCS in repSCS. For the replicated samples and LBS, the ACA remained relatively constant with time, and for the natural and replicated SFS, SCS and ALL they were found to be at $\sim 140^{\circ}$, whereas the LBS and repLBS were at $\sim 125^{\circ}$.

This study suggests that organic matter and residual water content dominate the efficiency of the DMDCS treatment. A possible reason for the higher DMDCS consumption for the natural soils (Fig. 3) is that the soil particles are not fully covered with the water-repellent layer at low DMDCS concentrations, probably owing to the DMDCS reacting with the residual water to form long chains of PDMS and thus reducing the number of molecules available to bond with the $-\mathrm{OH}$ groups in the soil. At high concentrations, the DMDCS molecules outnumber the number of sites available, even if long chains of PDMS are formed.

\section{CONCLUSION}

This study has shown that the treatment of a soil with DMDCS to induce water repellency is very sensitive to the soil components. The presence of residual water, organic matter and other non-mineral matter strongly constrains and delays the development of water repellency. In particular, the results revealed that less than $0 \cdot 005 \%$ DMDCS was sufficient for clean soil particle surfaces to reach the maximum water repellency with no further changes with time. As a new technology, it would be preferable to induce water repellency in crushed rocks due to the lower consumption of DMDCS and their post-treatment stability.

\section{ACKNOWLEDGEMENTS}

Comments on the paper by $\mathrm{Mr}$ Yunesh Saulick and Mr Shuang Zheng and laboratory support by Mr T. C. Chan, $\mathrm{Mr}$ Keith Wong and Mr N. C. Poon are acknowledged.

\section{REFERENCES}

Bachmann, J., Ellies, A. \& Hartge, K. H. (2000). Development and application of a new sessile drop contact angle method to assess soil water repellency. J. Hydrol. 231-232, 66-75.

Bardet, J. P., Jesmani, M. \& Jabbari, N. (2014). Permeability and compressibility of wax-coated sands. Géotechnique 64, No. 5, 341-350, http://dx.doi.org/10.1680/geot.13.P.118.

Bisdom, E. B. A., Dekker, L. W. \& Schoute, J. F. T. (1993). Water repellency of sieve fractions from sandy soils and relationships with organic material and soil structure. Geoderma 56, 105-118.
Byun, Y. H., Tran, M. K., Yun, T. S. \& Lee, J. S. (2011). Strength and stiffness characteristics of unsaturated hydrophobic granular media. ASTM Geotech. Testing J. 35, No. 1, 1-8.

Doerr, S. H. (1998). On standardising the 'water drop penetration time' and the 'molarity of an ethanol droplet' techniques to classify soil hydrophobicity: a case study using medium textured soils. Earth Surf. Processes and Landforms 23, No. 7, 663-668.

Doerr, S. H., Shakesby, R. A. \& Walsh, R. P. D. (2000). Soil water repellency, its characteristics, causes and hydrogeomorphological consequences. Earth Sci. Rev. 51, No. 1-4, 33-65.

Fink, D. H., Frasier, G. W. \& Cooley, K. R. (1980). Water harvesting by wax-treated soil surfaces: progress, problems, and potential. Agric. Water Managmt 3, No. 2, 125-134.

Gao, L. C. \& McCarthy, T. J. (2006). A perfectly hydrophobic surface $($ theta(A) $/$ theta $(\mathrm{R})=180$ degrees/180 degrees). J. Am. Chem. Soc. 128, No. 28, 9052-9053.

Goebel, M., Woche, S. K., Bachmann, J., Lamparter, A. \& Fischer, W. R. (2007). Significance of wettability-induced changes in microscopic water distribution for soil organic matter decomposition. Soil Sci. Soc. Am. J. 71, No. 5, 1593-1599.

$\mathrm{Ju}, \mathrm{Z}$., Ren, T. \& Horton, R. (2008). Influences of dichlorodimethylsilane treatment on soil hydrophobicity, thermal conductivity, and electrical conductivity. Soil Sci. 173, No. 7, 425-432.

Lee, C., Yang, H. J., Yun, T. S., Choi, Y. \& Yang, S. (2015). Water-entry pressure and friction angle in an artificially synthesize water-repellent silty soil. Vadose Zone J. 14, No. 4, http://dx.doi/org/10.2136/vzj2014.08.0106.

Lourenço, S. D. N., Jones, N., Morley, C., Doerr, S. H. \& Bryant, R. (2015a). Hysteresis in the soil water retention of a sand-clay mixture with contact angles lower than ninety-degrees. Vadose Zone J. 14, No. 7, http://dx.doi.org/10.2136/vzj2014.07.0088.

Lourenço, S. D. N., Woche, S. K., Bachmann, J. \& Saulick, Y. (2015b). Wettability of crushed air-dried minerals. Géotechnique Lett. 5, No. 3, 173-177, http://dx.doi.org/10.1680/geolett.15. 00075.

Osborn, J. F., Pelishek, R. E., Krammes, J. S. \& Letey, J. (1964). Soil wettability as a factor in erodibility. Soil Sci. Soc. Am. Proc. 28, 294-295.

Shen, X., Zhou, T. \& Ye, L. (2012). Molecular imprinting of protein in Pickering emulsion. Chem. Commun. 48, No. 66, 8198-8200.

Soeno, T., Inokuchi, K. \& Shiratori, S. (2004). Ultrawater-repellent surface - fabrication of complicated structure of $\mathrm{SiO} 2$ nanoparticles by electrostatic self-assembled films. Appl. Surf. Sci. 237, No. 1-4, 539-543.

Wijewardana, N. S., Kawamoto, K., Moldrup, P., Komatsu, T., Kurukulasuriya, L. C. \& Priyankara, N. H. (2015). Characterization of water repellency for hydrophobized grains with different geometries and sizes. Environ. Earth Sci. 74, No. 7, 5524-5539, http://dx.doi.org/10.1007/s12665-015-4565-6. 